\title{
Seroprevalence of Hepatitis Bs antigen among pregnant women visiting primary health care centers in Baghdad Al-Jadeda sector in Baghdad.
}

\author{
Shayma S. Ali* \\ Ban A. Ridha Salman*
}

\author{
FICMS/FM \\ FICMS/FM
}

\section{$\underline{\text { Abstract }}$}

Background: Hepatitis B is a potentially life-threatening liver infection which is caused by the hepatitis B virus. Universal testing of hepatitis B virus of pregnant women already occurs in many parts of the world, but still suboptimal in resource-limited settings.

JFac Med Baghdad 2018; Vol.60, No .1 Received Dec. 2017 Accepted Mar. 2018
Objectives: To find the seroprevalence of hepatitis B s antigen in pregnant women visiting primary health care centers in Baghdad Al-Jadeda health sector that belongs to Baghdad Al-Rusafa health directorate and to determine the effect of some social and obstetrical factors in the infected women.

Patients and Methods: A retrospective cross-sectional study carried on 6975 records of pregnant women visited primary health care centers from $1^{\text {st }}$ of January 2016 to 30th of June 2017, whose blood samples were tested at the time of visits for hepatitis B s antigen in the reference laboratory and confirmation tests were established in the central public health laboratory in Baghdad for positive cases and included in their records. The effect of certain sociodemographic and obstetrical factors was also assessed in the study.

Results: Of total number of 6975 pregnant women records, hepatitis B s antigen was positive for 11, two were excluded to avoid duplication of data and the final number of infected pregnant women was 9 with prevalence rate of $0.13 \%$. No important findings from their antenatal records regarding effect of certain sociodemographic and obstetrical factors were found except that husband of the majority of cases (55.6\%) were HBs Ag negative and no information available about rest of the cases (44.4\%).

Conclusion: There was a low prevalence of hepatitis B among studied pregnant women. We also concluded that source of infection to these women was mainly parenteral rather than sexual.

Keywords: hepatitis B virus, hepatitis B s antigen, pregnant women.

\section{Introduction:}

Hepatitis B is a potentially life-threatening liver infection which is caused by the hepatitis B virus and it is a major global health problem that can cause chronic infection and puts people at high risk of death from cirrhosis and liver cancer (1). "An estimated 2 billion persons worldwide have been infected with hepatitis B virus and more than 350 million persons have chronic, lifelong infections" (2). Hepatitis B virus is found worldwide with differing levels of endemicity and the majority of the world's population live in countries where the endemicity of hepatitis B in the general population is high ( $\geq 8 \%$ ) or intermediate (2-7\%)(3). According to the WHO, hepatitis B prevalence in Eastern Mediterranean Region which Iraq is part of, estimated as $3.3 \%(1)$. "In Iraq, hepatitis B virus infection has declined in the past few decades as hepatitis B in blood donors was 3.6\% in 1973, 4.1\% in 1984 to less than $1 \%$ in the nineties. This reduction was the result of the prevention and control programs adopted by the

*Al -Thubat health center Baghdad health center Email: salmanshayma@yahoo.com. government, such as safe injections, safe blood transfusion and introduction of the vaccination program (4). " "Perinatal transmission of hepatitis B virus from mother to infant at birth is very efficient and if the mother is positive for both HBsAg and HbeAg so $70 \%-90 \%$ of infants will become infected in the absence of post exposure prophylaxis, the risk of transmission is about $10 \%$ if the mother is positive only for HBsAg. As many as $90 \%$ of infant hepatitis B virus infections will progress to chronic infection (2)." The key strategy for controlling infection in Iraq is prevention of hepatitis B virus transmission from mother to infant which takes place in utero, during delivery, and after birth. Vaccination after birth is of efficacy in preventing hepatitis B virus infection in infant during delivery and after birth, but it cannot interrupt hepatitis B virus intrauterine infection (5). Nationally in Iraq, $88 \%$ of newborn infants in a given recent year received their first dose of hepatitis B vaccine within first 24 hours of life and $89 \%$ of one-year-olds (ages $12-23$ months) received three doses of the hepatitis $\mathrm{B}$ vaccine. "There is a national policy that specifically targets mother-tochild transmission of hepatitis $\mathrm{B}$ including that all 
pregnant women should be screened for hepatitis B (at primary health centers), all pregnant women found to have hepatitis $\mathrm{B}$ are counselled and all infants receive their first dose of hepatitis $B$ vaccine within 24 hours of birth (6)." So the (aim of this study) is to measure the seroprevalence of hepatitis $\mathrm{B} s$ antigen in (pregnant women) visiting primary health care centers in one of health sectors belongs to Baghdad Al-Rusafa health directorate and to determine some social and obstetrical factors in the infected women.

\section{Subject and Methods:}

A retrospective "cross-sectional" study based on the review of records of the reference laboratory of Baghdad Al-Jadeda sector that receives screening blood samples for hepatitis B s antigen of pregnant women from all primary health care centers related to Baghdad Al-Jadeda sector, which are 8 centers and on the antenatal records in the primary health care centers, no interviews were done with the study sample. A total number of 6975 records of pregnant women visited primary health care centers from $1^{\text {st }}$ of January 2016 to 30th of June 2017 were included in the study, of which the results of blood samples of the pregnant women tested for HBsAg in the reference laboratory using ELISA technique and the confirmation tests for positive cases which were established in the central public health laboratory in Baghdad using western blot technique were reviewed For positive cases "socio-demographic" factors as age, occupation, educational level and husband history of infection with hepatitis B and obstetrical factors as number of pregnancies, previous abortion, still birth and previous cesarean section were further assessed depending on the antenatal records to find if there is any effect of these factors on hepatitis B infection in these cases.

Inclusion criteria: pregnant women visited primary health care centers from $1^{\text {st }}$ of January 2016 to 30th of June 2017 seeking for antenatal care and hepatitis B s antigen screening done for them, were included in the study.

Ethical considerations: permission from Baghdad Al-Rusafa health directorate for collection of data and performance of the study.

Statistical analysis: SPSS version 20 was used, frequencies and percentages were calculated.

\section{Results:}

A total number of 6975 pregnant women records were reviewed, hepatitis B s antigen was positive for 11, two were excluded to avoid duplication of data as these two women were pregnant in year 2016 and get pregnant again in year 2017 and test for HBs Ag reported for them in each pregnancy in the reference laboratory records, so they were included once in our data and the final number of infected pregnant women was 9 with prevalence rate of $0.13 \%$.

For socio-demographic factors all the infected women were under 35 years of age one case was under 20, the other cases mostly evenly distributed between age categories (table 1).

(For occupation it was found that all 9 cases were housewives (table1).

For education level, five (55.6\%) of the cases were graduated from intermediate school, one case has diploma, no cases had college or higher education level (table1).

Husband of five (55.6\%)of the cases were negative for HBs Ag as they were screened in the reference laboratory, no screening record found in the reference laboratory for husband of other $4(44.4 \%)$ cases, so they were considered as unknown (table1). Obstetrical factors were also analyzed, number of pregnancies found to be 4 or more in 6 (66.7\%) of infected women and 2 (22.2\%) has 2 or 3 pregnancies and one (11.1\%) was pregnant for the first time (table2). We also found $4(44.4 \%)$ cases had history of cesarean section,5 (55.6\%) had history of abortion and only 2 (22.2\%) had history of still birth (table2).

Table 1: Socio-demographic factors for the infected pregnant women with HBs Ag.

\begin{tabular}{|c|c|c|}
\hline $\begin{array}{l}\text { Socio-demographic } \\
\text { factors } \\
\text { Age }\end{array}$ & Frequency & Percent \\
\hline $15-19$ & 1 & 11.1 \\
\hline $20-24$ & 3 & 33.3 \\
\hline $25-29$ & 2 & 22.2 \\
\hline $30-34$ & 3 & 33.3 \\
\hline Total & 9 & 100.0 \\
\hline Education level & Frequency & Percent \\
\hline illiterate & 1 & 11.1 \\
\hline primary school & 1 & 11.1 \\
\hline $\begin{array}{l}\text { intermediate } \\
\text { school }\end{array}$ & 5 & 55.6 \\
\hline secondary school & 1 & 11.1 \\
\hline diploma & 1 & 11.1 \\
\hline Total & 9 & 100.0 \\
\hline $\begin{array}{l}\text { Husband infection with } \\
\text { HBV }\end{array}$ & "Frequency" & Percent \\
\hline no & 5 & 55.6 \\
\hline unknown & 4 & 44.4 \\
\hline Total & 9 & 100.0 \\
\hline Occupation & Frequency & Percent \\
\hline Housewives & 9 & 100.0 \\
\hline Employed & 0 & 0.0 \\
\hline Total & 9 & 100.0 \\
\hline
\end{tabular}


Table2: Obstetrical factors for the infected pregnant women with $\mathrm{HBs}$ Ag.

\begin{tabular}{|c|c|c|}
\hline $\begin{array}{l}\text { Obstetrical factors } \\
\text { number of pregnanc }\end{array}$ & Frequency & Percent \\
\hline 1 & 1 & 11.1 \\
\hline $2-3$ & 2 & 22.2 \\
\hline 4 and above & 6 & 66.7 \\
\hline "Total" & 9 & 100.0 \\
\hline cesarean section & "Frequency" & Percent \\
\hline yes & 4 & 44.4 \\
\hline no & 5 & 55.6 \\
\hline Total & 9 & 100.0 \\
\hline abortion & "Frequency" & Percent \\
\hline yes & 5 & 55.6 \\
\hline no & 4 & 44.4 \\
\hline "Total" & 9 & 100.0 \\
\hline still birth & "Frequency" & Percent \\
\hline yes & 2 & 22.2 \\
\hline no & 7 & 77.8 \\
\hline Total & 9 & 100.0 \\
\hline
\end{tabular}

\section{Discussion:}

" Universal testing of hepatitis B virus of pregnant women already occurs in many parts of the world, but still suboptimal in resource-limited settings and "the most important preventive strategy for transmission of hepatitis B virus from mother to infant is to deliver the first dose of hepatitis B vaccine as soon as possible after birth, preferably within 24 hours of birth followed by at least two timely subsequent doses (7)." Recent studies showed the role for antiviral therapy in the third trimester which may be effective in hepatitis B infected pregnant women to further reduce the risk (7). For this reason, in the current study we were trying to find the overall "prevalence of hepatitis $\mathrm{B}$ in pregnant women" during their antenatal visits to primary health care centers that was found to be (0.13\%) which reflect low prevalence. "The prevalence of hepatitis B infection in the general population" in Iraq is not available and that is due to the unstable political and social situation for the past decades (4). In Iraq, the national survey between 2005 and 2006 showed that the prevalence rate of HBsAg was $1.6 \%$ and correlated positively with age (8). Regarding pregnant women in Iraq, published data about hepatitis B prevalence is very poor. A case-control study done in Baghdad on 40 pregnant women between September 2010 to May 2011 showed Hepatitis B s antigen to be 5\% (8) which is considered high if compared to the current study, in addition this study was done on a very small sample visiting private sector and depended on different methodology from ours which make dependence on and comparison with its results not so that fruitful. "No other studies on prevalence of hepatitis B in pregnant women" in Iraq found during work in the current study. Al-Rubaye et al, in their study on hepatitis B seromarkers in blood donors in Basra, Iraq showed that hepatitis B s antigen prevalence was $0.2 \%$ which is close to our results (4). Other study that reflect low prevalence of HBsAg is that "among blood donors attending the National Blood Transfusion Center in Baghdad, Iraq from 2006-
2009" which was $0.7 \%$ (9), which is very close to the study performed on donors of blood bank in Duhok, Iraq in $1^{\text {st }} 9$ months of 2014 performed by Nawfal Rasheed et al where HBsAg prevalence was $0.78 \%(10)$. The prevalence in the current study is lower than that seen in Saudi pregnant women in AlRiyadh where The prevalence of sero-positive HBsAg was $1.6 \%$ in a study done from June 2005 to June 2006 (11) and lower than that seen in a study done on pregnant women of seven provinces in Iran during $1^{\text {st }} \quad 3$ months of 2011 where HBsAg prevalence among tested women was $1.2 \%$ (12). Higher HBsAg prevalence (4.3\%) found among Jordanian pregnant women (13). Comparing the current study results to those in India HBsAg prevalence was found to be $1.01 \%$ in a study done in south India (14) and $1.11 \%$ in northern India (15) which is considered low prevalence although being again higher than that of the current study results. Regarding sociodemographic factors, it was found that all of positive cases were of low education level except one who had diploma and all of them were housewives which was close to the result found by Preetkanwal Sibia et al in their study on pregnant women in northern India (15) where majority of infected women were housewives. It was also found that husband of the majority of cases (55.6\%) were HBs Ag negative and no information available about rest of the cases (44.4\%) which indicate that mode of transmission of "hepatitis B infection" in those pregnant women was mainly not sexual but due to other modes as parenteral transmission which may be due to lack of infection control practices in certain dental and surgical settings especially in private sector in Iraq, as we found that majority of cases $(66.7 \%)$ had 4 and more pregnancies with $55.6 \%$ had history of abortion and $44.4 \%$ with history of cesarean section that might expose those pregnant women to contamination and infection. Limitation of the study: as the data was collected retrospectively from reference laboratory and antenatal clinics records, so many factors like hepatitis B vaccination status of the pregnant women, their previous surgical and dental operations and others could not be assessed.

\section{Conclusion:}

Based on the on the results of the current study, "there was low prevalence of hepatitis B among studied pregnant women," with no prominent effect of sociodemographic factors studied as age, occupation and level of education. We also concluded that source of infection to these women were mainly parenteral rather than sexual as their husbands were in majority not infected or unknown cases, in addition to some obstetrical factors as parity four and more and abortions which were found in majority of the cases and may indicate contamination as source of parenteral infection. 


\section{Authors' contribution:}

Both authors worked together in collecting data from records of reference laboratory and for positive cases sociodemographic and obstetrical data from antenatal records and analyzed the data statistically.

\section{References:}

1. Hepatitis B (fact sheet). WHO. July 2017. Available through: http://www.who.int/mediacentre/factsheets/fs204/en/ . Accessed 19/7/2017.

2.epidemiology and prevention of vaccine preventable diseases (the pink book). CDC; 2015 $13^{\text {th }}$ ed. Available through: http://www.cdc.gov/vaccines/pubs/pinkbook/.

Accessed 22/7/2017.

3. Hepatitis B (fact sheet). WHO. 2017. Available through:

http://www.who.int/ith/diseases/hepatitisB/en/.

Accessed 19/7/2017.

4. Ali Al-Rubaye, Ziad Tariq and Laith Alrubaiy. Prevalence of hepatitis $B$ seromarkers and hepatitis $C$ antibodies in blood donors in Basra, Iraq. BMJ open gastroenterology; 2016; v.3(1). Available though:

https://www.ncbi.nlm.nih.gov/pmc/articles/PMC478 2278/. Accessed 2/7/2017.

5. Hujaz Ismail. Hepatitis B virus infection in pregnant women in Baghdad. Alkindy college medical journal; June 2013; 9 :42-45.

6.Global policy report on the prevention and control of viral hepatitis. WHO; 2013. Available through: who.int/iris/bitstream/10665/85397/1/978924156463 2_eng.pdf. Accessed 17/7/2017.

7. Guideline on hepatitis $B$ and $C$ testing. WHO; February 2017. Available through: www.who.int/hepatitis/publications/guidelineshepatitis-c-b-testing/en/. Accessed 17/7/2017.

8. Batool Mutar Mahdi, May Saour, Hujaz Ismail Abdulrazzaq. Evaluation of Hepatitis $B$ virus infection in pregnant women. International journal of biomedical research; 2015; 6: 379-381.
9. Turky M. Ataallah, Khaleel A. Hanan, Kadoori S. Maysoun, et al. Prevalence of hepatitis $B$ and $C$ among blood donors attending the National Blood Transfusion Center in Baghdad, Iraq from 20062009. Saudi medical journal; 2011; 32(10): 10461050.

10. Nawfal Rasheed Hussein, Sefar Mohamad Haj, Lokman Amin Almizor, et al. The prevalence of hepatitis Band $C$ viruses among blood donors attending blood bank in Dukok, Kurdstan Region, Iraq. International journal of infection; 2017 ;4(1): e39008. Available through: http://intjinfection.com/en/articles/14774.html. Accessed 28/6/2017.

11. Mohammed A. Alrowaily, Mostafa A. Abolfotouh, Mazen S. Ferwanah. Hepatitis B Virus Sero-Prevalence Among Pregnant Females in Saudi Arabia. Saudi Journal of Gastroenterology; 2008; 14(2): 70-72.

12. Alireza Shoghli, Seyed Mahmood Nabavi, Seyed Moayed Alavian, et al. Hepatitis B surface antigen prevalence in pregnant women: A cross-sectional survey in Iran. International Journal of Preventive Medicine; Des.2014; 5(3): 2013-2018.

13. Naji Batayneh and Salwa Bdour. Risk of perinatal transmission of hepatitis B virus in Jordan. Infectious diseases in obstetrics and gynaecology; 2002; 10: 127-132

14. Sathiyakala Rajendiran, Ushadevi Gopalan, Karthika Jayakumar. Seroprevalence of Hepatitis B infection among pregnant women in South India. International Journal of Reproduction, Contraception, Obstetrics and Gynecology; 2017; 6(1): 249-251.

15. Preetkanwal Sibia, Manjit Kaur Mohi, Amith Kumar. Seroprevalence of Hepatitis B Infection among Pregnant Women in One of the Institute of Northern India. Journal of clinical and diagnostic research; Aug. 2016; 10(8): QC08-QC09. Available through:https://www.ncbi.nlm.nih.gov/pmc/articles/ PMC5028548/. Accessed 2/8/2017. 